\title{
Astronomers and physicians: so far away and so close at the same time
}

\section{Abstract}

In this paper we included the participation and contributions of some important doctors in the development of astronomy and their legacy.

Keywords: doctors, astronomy, physicists
Volume 4 Issue 6 - 2020

\section{Ernesto Arriaga-Morales}

Professor at ALGIA Center for Medical Education, Chief at the ED of San Angel Inn Sur Hospital, Mexico

Correspondence: Ernesto Arriaga-Morales M.D, Professor at ALGIA Center for Medical Education, Chief at the ED of San Angel Inn Sur Hospital, Mexico, Email earriaga_2@hotmail.com

Received: November 13, 2020 | Published: November 24, 2020

\section{Introduction}

As an emergency physician it would be unacceptable that I will order a treatment according to the position of the stars and planets, but it wasn't always like that. On the other side as an amateur "astronomer", or better "an enthusiastic fan of the cosmos" I believe that the understanding of physics and astronomy is much closer than we believe to the understanding of the human body, our bones for example are conformed by calcium and phosphorus, that were created most probably of freshly synthesized material from a supernova being added to the proto-solar nebula. ${ }^{1,2}$ On the seventeenth and eighteenth centuries there was a close relationship between medicine and astronomy, it was an obligatory knowledge for every physician. Herbal remedies have to be administered according to planetary positions, even the position of the stars was believed to be of prognosis value for patients, to become a great physician you should be first a great astronomer. ${ }^{3}$ There were retractors for this dogma, Manardi questioned this belief, he said that pulsations of the veins are a surer guide than the configurations of heavens. He believed that astronomy smear and corrupt the distinguished and chaste art of medicine. Obviously not many doctors and people shared Manardi's ideas, a few centuries later the idea of the heavens guiding the health of people still was the "Standard of Care".

\section{Historical relations between the medicine and astronomy}

During the next pages we will travel through the history of medicine and astronomy.

\section{Paolo dal Pozzo Toscanelli (1397-|482)}

Toscanelli was an Italian mathematician, astronomer and cosmographer, learned mathematics in the University of Padua, and get the degree of Medicine Doctor on 1424, he made observations of comets and their orbits, including the Halley on 1456. But actually, he write almost anything. On June of 1464 send a letter with a map to an old friend Fernando Martíns de Roriz, exposing the idea of arriving to the island of the spices by sailing to the west, years later Hernando Colón get access to this letter which included a very bad calculi of the circumference of the earth $(29,000 \mathrm{~km}$ vs the real $40,000 \mathrm{~km})$ this huge mistake was caused because he used the data of Ptolomeo, this confusion cheer Colón to take the risk of the travel and make him believe that the islands of the Caribe were actually Antillia. On the moon we have a crater named after him and an asteroid (8209).

\section{Niklas Koppernigk ( | 473- | 543)}

He was a prusian astronomer who formulated after 25 years of work the heliocentric theory of the solar system, (first conceived by Aristarco de Samos 310-230 a.C.). His book "De Revolutionibus Orbium Coelestium", (about the revolutions of the celestial spheres) is considered to be the foundation of the modern astronomy. He studied in Mathematics in Cracovia (1491-1494), later traveled to Bolonia (14961499) where he studied Law, Medicine, Ancient Greek, Phylosophy and on 1500 he traveled to Rome where he worked as an assistance to Domeico da Novara (an astronomer) a year later he returned home and was appointed Canon in the Frauenburg Cathedral. This same year he returned to Padua to study Law and Medicine, and obtained on 1503 the degree of Canonic Laws. He was finally reinstaled in Prusia on 1523, where he dedicated to administer the Warmia Dioceses, practiced medicine and began his huge work in astronomy. It is important to consider that for Niklas astronomy wasn't more than a distraction, but his theory is one of the most important contribution to the science in the history. He published his theory on 1543 (year of his dead); and his books were included in the "Index Librorum Prohibitorum", (the prohibited book index) next to the ones of Galileo.

The central ideas of Niklas were:

I. The celestial movements are uniform, eternal and circular, or composed by diverse cycles.

II. The center of the universe is the Sun

III. Orbiting around the Sun, in order they are Mercury, Venus, Earth, the Moon, Mars, Jupiter and Saturn.

IV. The stars are distant objects that remain fixed and then don't orbit around the sun.

V. The earth has 3 movements, daily rotation, annual revolution and annual inclination. The retrograde movement of the planets is explained by the movement of the earth.

VI. The distance between the earth and Sun is smaller than the distance with the stars. 
The mediaeval ideas were changed completely the substitution of the closed and hierarchical cosmos with the man as the center of the universe by and more homogeneous and indeterminate cosmos situated around the Sun. At the same time the conception of the man was changed, postulating that the man is now governed by the reason, making the change to a man that is autonomous in his capacity of reasoning and being available to control and dominate the nature, and leaving the conception of being the center of the universe. Facing the world and not only contemplating it. A Lunar crater and an asteroid (1322) are named after him, also a 5 marks silver coin in the German Federal Republic on 1973 commemorated the 500 anniversary of Copernicus birth. on 2010 the Copernicus Science Center in Varsovia was inaugurated, in New York exist the Kopernik observatory. Also, the Copernicus Programme of the European Aerospace Society is named after him. In chemistry they also honored him by naming the element 112 Copernicium on 2010.

\section{Mario Girolamo Fracastoro ( I 483- | 553)}

He was an italian doctor and as other Renaissance physicians owned a complete and extense knowledge including astronomy, actually he shared time with Copernicus in Padua's university. He is considered the father of the epidemiology, writed three key books, one is a poem "Syphilis sive morbus Gallicus" that describe a new disease "Syphilis", the other one is much more importante, "De contagione et contagiosis morbis" which provides a new theory about the spread of diseases and is considered the first text in medicine about this. As other figures of this age, he was prolific in knowledge, he studied laws in Verona on 1478, before entering to Padua on 1501, where he studied mathematics, medicine and philosophy and obtained the degree of bachelor on 1502. He retired a year later and moved to Verona where he practiced medicine with great success, there he described the new disease and named it, on 1538 he wrote later he writed "Homocentrica sive de stellis liber" were he foreshadowed the Copernicus model. Later De contagion et contagiosis morbis" on 1546, in this master piece with a great comparison, observation and reasoning, postulating three possibilities to explain the spread of diseases: first that the diseases are spread by direct contact; second that it is spread through "fomes" (fomites), that are vectors of infection that host the essential seed of contagion an causes the infection; and third is distance spread. He was honored and requested by clergy and the royalty, even the pope Paulo III, named him "medicus Ordinarius" after his fight against the plague. The asteroid Fracastoro (3625) is named after him.

\section{Paracelsus (1493-I54I)}

He was an Swedish alchemist, physician and astrologer, he chose his name which means "similar to Celsus", Celsus was a physician of the first century, (original name: Theophrastus Phillippus Aureolus Bombastus von Hohenheim) he was famous for many things, for example he named the Zinc (Zincum), is considered the father of the toxicology thanks to his famous quote "dosis sola facit venenum" (The dose make the poison). He was considered a revolutionary, thinking out the box, and at the same time he maintained the astronomy and mysticism as a relevant part of his knowledge. The cosmic order and the Astrum in corpore doctrine were his prime and most loved idea, considering the man as a microcosmos, he placed the firmament inside man's body and designed it as Astrum or Sydus. The endosomatic sky and it's stelar course was close related to the individual constellation (horoscope). ${ }^{3} \mathrm{He}$ established four pillars for medicine: Astronomy, Natural Sciences, Chemistry and love; believed that only a virtuous man can be a good doctor. He has a Lunar crater and the asteroid (2239) commemorating his name.

\section{Edmond Modeste Lescarbault ( $18|4-| 894)$}

Was a French doctor and an amateur astronomer. He graduated and obtained his diploma in medicine on 1848 . He then started to work as a doctor in Orgères-enBeauce and worked there until. As an enthusiastic astronomer he built an observatory with a $95 \mathrm{~mm}$ refractor, on march 26, 1859 he saw a small object transiting the Sun, at first he thought that the object could be a sunspot, but aftertaking a second look he realized that the object was actually moving, the previous year he saw the transit of Mercury and guessed that he was observing the transit of a previously undiscovered body. As a good scientist he took some hasty measurements of its position and direction of motion, using a pendulum and a clock with wich he took his patients pulses, he estimated with impressive precision the duration of the transit at 1 hour, 17 minutes and 9 seconds. he remembered Le Verrier's theory of an intramercurial planet named Vulcan, he wrote a letter to the astronomer and get visited by him on December of this same year, they announced the discovery on January 2 of 1860, Edmond became Chevalier of the Légion d'honneur and was invited to appear before numerous learned societies. ${ }^{4}$

Lescarbault's discovery was rejected by many astronomers, for different reasons, for example the complexity and the danger involved in pointing the telescope directly to the sun, or that the huge amount of light present even quite far away from the Sun can produce undesided reflections inside the optics, producing false objects for the observer, but Emmanuel Liais an eminent French astronomer who was working for the Brazilian government in Rio de Janeiro, claimed to have been looking at the surface of the Sun with a mure powerful telescope at the very moment and observed the mysterious transit. ${ }^{4}$ The existence of the Vulcan planet was predicted by the fluctuations of Mercury's orbit, that was resolved on 1915 with the theory of relativity, which predicted exactly the observed amount of advance of Mercury's perihelion without the needing for the existence of a hypothetical Vulcan. This theory was empirically verified on May 29 of 1919, during a total solar eclipse by measuring the bending of sunlight, convincing most of the astronomers that a large planet inside the orbit of Mercury is not possible. The huge amount of light present even quite far away from the Sun can produce false reflections inside the optics, thus fooling the observer into seeing things that do not exist. From 1859 to 1915 many eminent and amateurs' astronomers embarked in the search of the Vulcan, after many years we know that the alleged intra-mercurial objects exist, being nothing more than comets or small asteroids, searches have ruled out asteroids larger than $6 \mathrm{~km}$, neither SOHO nor STEREO has detected a planet inside the orbit of Mercury.

Lescarbault's manuscripts, including correspondence with Camille Flammarion, are kept in Bibliothèque Municipale in Châteaudun. $\mathrm{He}$ died on 1894. The street where he lived and worked as a physician was named after him.

\section{Henry Draper ( $1837-\mid$ 882)}

He was an american physician, telescope maker and an amateur astronomer, he always worked with his wife Mary Anna Palmer Draper (the actual astronomer), they made a reflector telescope combining the William Herschel metallic mirrors with the Justus con Liebig silver treatment, obtaining durable silver films. On 1862 they finished a $39 \mathrm{~cm}$ mirror, and on 1872 they completed a $71 \mathrm{~cm}$, with this one they captured the spectrum of the star Vega, in which they could appreciate 5 lines. Anna was also a great photographer and they were the first to photography the Orion nebulose on 1880. ${ }^{5}$ After Henry's dead on 1882 Anna awarded memorial fund to the Harvard College's Observatory, with the objective of completing the Henry's Drape 
catalog of stelar spectrums. ${ }^{6}$ Their influence, helped Henrietta Swan Leavitt to study the variable stars (Cepheids) which bright variate in regular periods, establishing the relation between the period and the bright of the stars. ${ }^{5,6}$ Henry has a lunar crater named after him (The Draper Crater).

\section{Boris Borisovich Yegorov (1937-1994)}

Was a Soviet Physician and cosmonaut, actually he was the first physician that make the jump from watching through a telescope to make a space flight. He was born in Moscow on November 26 of 1937, son of one of the Soviet Union's leading brain surgeons. He went to medical school and chose aviation and space medicine as his specialty. ${ }^{7}$ Dr. Yegorov and other two cosmonauts were launched aboard the Voskhod (Sunrise) 1 spacecraft from the Baikonur space center in Kazakhstan on October 12, 1964, on the seventh manned Soviet space flight. ${ }^{?}$

The flight was the first with more than one astronaut, the first with trained scientists and the first space flight without space suits, (maybe because the spaceship was created for one cosmonaut). The travel was a 24 hour travel including 16 orbit flights, Dr. Yegorov was 27 years old lieutenant in the Soviet Army's medical corps, he was the first to study the effects of microgravity, took some blood samples and made an experiment with fruit flies and plants. An editorial in The New York Times claimed: "Space is no longer the exclusive preserve of the astronaut; now many sciences will look forward to preparing some of their practitioners to use their knowledge and skills outside this planet and to bring back new knowledge for the benefit of mankind." ${ }^{\text { Later in }}$ his career he was the head of a number of medical research institutions in Russia. From 1984 to 1982, he was the director of the ScientificIndustrial Center for Medical Biotechnology under the Soviet Health Ministry. ${ }^{7,8}$ Dr. Yegorov was awarded some of his nation's highest decorations, including the gold star of the Hero of the Soviet Union and the Order of Lenin. Boris B. Yegorov, the first physician to fly in space, died in his apartment in Moscow on a Monday night, he was 57 , The cause was a heart attack. ${ }^{8}$

\section{Carl Edward Sagan (1934-| 996)}

Astronomer, astrophysic, astrobiologist, writer, science divulgator, and unfortunately not a physician, but someone to include in this list, Why? Simple because most of today's elite or amateur astronomers grew watching or reading him, He was a defender of the skeptical scientific think and the scientific method, he looked outside the earth for life (the SETI project) ${ }^{9}$ and even helped to send messages on space probes in order to inform extraterrestrial civilizations about the human culture. ${ }^{10}$ Was the first to study the greenhouse effect on the atmosphere of Venus. ${ }^{11}$ (maybe there are too much to talk about him). The television series "Cosmos: a personal Voyage" and the books where he was writer, co-writer or editor helped to expand the knowledge of the cosmos to everyone, with simplicity but always with rigor and coherence.

His parents weren't Scientifics, but actually that helped him to reach the mind of many people. On 1939, during the Universal Exposition in New York he saw the time capsule on Flushing Meadows, which contained objects from 1930 to be recovered for future generations, this idea (with other ones) permeated deeply in Sagan, the Pioneer's plaque and the Voyager's disc were time capsules to be recovered by distant extraterrestrial civilizations. ${ }^{10,11}$ On January 1 of 1996, during an interview for "Psychology Today" he said: "Every kid starts out as a natural-born scientist, and then we beat it out of them. A few trickles through the system with their wonder and enthusiasm for science intact". Beside the innumerable medals, trophies, an attempt to name a computer after him, and many texts, the most important thing that he left us is the need to spread the science to every kid to stimulate the curiosity to understand the world, the cosmos and they selves.

\section{Today's relationship between astronomy and medicine}

The medicine has been close to the astronomy from the very beginning, changing progressively, but today they are closer than ever: neutron therapy for cancer patients, foldable walkers for the ones who can't walk alone, monitoring system for hospitals, computed tomography and magnetic resonance imaging for viewing inside our bodies, muscle stimulator devices for preventing muscle atrophy in paralyzed patients, a radiation free way to measure bone flexibility using vibration, foam cushioning to prevent ulcers, relieve pressure or simply to provide a better night's sleep, surgically implantable heart pacemaker and its cousin the implantable heart defibrillator, use technology from the space to continuously monitor patient's heart and to communicate information to the physician, for example, when to replace the battery, also the telemetry used in most hospitals is an inheritance from the equipment used for monitoring the astronauts health during the space travels. As I said before simply think about the calcium in your bones and remember it came from a super nova star explosion. ${ }^{12}$

\section{Acknowledgments}

None.

\section{Conflicts of interest}

The author declares there is no conflict of interest.

\section{References}

1. Herbst W, Rajan RS. On the role of a supernova in the formation of the solar system. Icarus. 1980;42(1):35-42.

2. Cameron A, Truran J. The supernova trigger for formation of the solar system. Icarus. 1977;30(3):447-461.

3. Petrovska B. Historical review of medicinal plants' usage. Pharmacognosy Reviews. 2012;6(11):1.

4. Baum R, Sheehan W. In Search of Planet Vulcan. $1^{\text {st }}$ edn. Vol. 1. Columbia, Columbia: Springer; 1997.

5. Asimov I. Historia del telescopio. Madrid, Madrid: Alianza; 1986.

6. Woodman J. The Women 'Computers' Who Revolutionized Astronomy . The Atlantic. Atlantic Media Company. 2017.

7. The Editors of Encyclopaedia Britannica. Boris Borisovich Yegorov. Encyclopædia Britannica. Encyclopædia Britannica, inc.; 2008.

8. Text of Brezhnev's Speech at Ceremonies in Red Square. The New York Times. The New York Times; 1964.

9. SETI. SETI Institute. 2012.

10. Sagan C. Carl Sagan's cosmic connection: an extraterrestrial perspective. Cambridge: Cambridge University Press; 2000.

11. Sagan C. Structure of the Lower Atmosphere of Venus. Icarus. 1962Apr3;1(1):151-160.

12. Blake GA. Carl Sagan's Life of Wonder and Skepticism. Chemical \&amp; Engineering News. 1999;77(50):44-45. 